\title{
PROTEÇÃO DO PATRIMÔNIO CULTURAL AMBIENTAL BRASILEIRO: OS INSTRUMENTOS DO SISTEMA NACIONAL DE CULTURA E OS DIREITOS AUTORAIS
}

\section{PROTECTION OF BRAZILIAN ENVIRONMENTAL CULTURAL HERITAGE: INSTRUMENTS OF NATIONAL CULTURE SYSTEM AND COPYRIGHT}

\author{
${ }^{1}$ Carolina Medeiros Bahia \\ ${ }^{2}$ Heloísa Gomes Medeiros
}

\begin{abstract}
RESUMO
O patrimônio cultural ambiental brasileiro é marcado pelo seu pluralismo e deve-se buscar meios para garantir sua existência e preservação. Para tanto, dentre os instrumentos existentes no ordenamento jurídico brasileiro destacam-se os planos de cultura, o tombamento e o registro. Adiciona-se a tais instrumentos as recentes discussões sobre o papel da propriedade intelectual, especialmente o direito autoral, nas políticas públicas nacionais sobre cultura.
\end{abstract}

Palavras-Chave: Patrimônio cultural ambiental; Planos de cultura; Tombamento; Registro; Direitos autorais.

\begin{abstract}
The Brazilian environmental cultural heritage is marked by its pluralism and we should seek ways to ensure its existence and preservation. For this, among the instruments of the Brazilian legal system we highlight the culture plans, the tombamento and the registration. In add to these instruments we have the recent discussions of the role of intellectual property, especially copyright, in national public policies on culture.
\end{abstract}

Keywords: Environmental cultural heritage; Cultural plan; Tombamento; Register; Copyright.

\footnotetext{
${ }^{1}$ Doutora em Direito pela Universidade Federal de Santa Catarina - UFSC, Florianópolis, (Brasil). Membro do GPDA/UFSC. Professora no Curso de Graduação e nos Programas de Mestrado Acadêmico e Profissional do CCJ/UFSC. E-mail: carolmbahia@gmail.com

${ }^{2}$ Doutoranda em Direito pela Universidade Federal de Santa Catarina - UFSC, Florianópolis, (Brasil).

Pesquisadora do GEDAI/UFPR. Bolsista da CAPES. E-mail: heloisamed@ gmail.com
} 


\section{INTRODUÇÃO}

O conceito de meio ambiente é compreendido, no Brasil, de maneira ampla, holística, abrangendo não apenas os recursos naturais como aspectos da interação entre o homem e a natureza. Daí falar-se, hoje, na existência tanto do meio ambiente natural, quanto artificial, do trabalho e cultural.

Desse modo, a cultura pode ser entendida como um dos elementos que integram o meio ambiente e, enquanto tal, indispensável para a manutenção da sadia qualidade de vida. Em virtude da sua essencialidade para a construção de nossa identidade multicultural, também desponta como garantia da preservação social dos povos e exercício do direito à memória (WOLFF, 2014), funcionando como anteparo contra a perda de identidade, um dos efeitos marcantes do atual processo de globalização.

A relevância da sua proteção também se dá em virtude da cultura funcionar como importante vetor de desenvolvimento econômico sustentável, na medida em que auxilia na diminuição, ainda que suave, dos desequilíbrios no intercâmbio de valores culturais em escala mundial (DRUMMOND; NEUMAYR, 2011, p. 35).

O objetivo do presente trabalho é o estudo do patrimônio cultural ambiental brasileiro, enfocando não apenas o conceito jurídico de cultura e seu tratamento pelo texto constitucional de 1988, como o recém instituído Sistema Nacional de Cultura - SNC e os principais instrumentos à disposição do poder público e da sociedade para sua proteção. Nesse cenário, o direito autoral apresenta-se também como elemento que precisa ser alinhado com as políticas nacionais de promoção, preservação e acesso à cultura, tendo em vista que o enrijecimento destes direitos pode causar prejuízos irreparáveis ao interesse coletivo e ao desenvolvimento do pluralismo cultural.

\section{CONCEITO JURÍDICO DE CULTURA}

Como conceito genérico e abstrato, a cultura pode ser definida sob diversas perspectivas teóricas (pode ser analisada sob o ponto de vista ético, religioso, filosófico etc), sendo que, dentre elas, a mais difundida leva em consideração a sua visão antropológica.

Apesar da sua relevância, o seu conceito antropológico está longe de ser uniforme e, atualmente, há muitas discussões em torno da sua definição. No entanto, o que há em comum 
entre todas as abordagens atuais de cultura é a compreensão de que ela é estruturada a partir de símbolos desenvolvidos pelos integrantes de cada realidade cultural, que todo ser humano atua na sua produção e que é precisamente este dado que possibilita existência de uma diversidade cultural.

Se do ponto de vista antropológico não é possível encontrar um conceito unívoco, sob o prisma jurídico, as dificuldades de conceituação da cultura são ainda mais aquilatadas, pois, muito embora a Constituição Federal de 1988 tenha dedicado uma seção própria para a cultura, impondo ao Estado o dever de garantir os direitos culturais aos cidadãos, não chegou a formular uma definição.

O texto constitucional apenas nos oferece, no caput do art. 216, um conceito auxiliar, o de patrimônio cultural brasileiro, que deve orientar a doutrina e a jurisprudência na compreensão do que é cultura, definindo-o como "os bens de natureza material e imaterial, tomados individualmente ou em conjunto, portadores de referência à identidade, à ação, à memória dos diferentes grupos formadores na sociedade brasileira".

As primeiras ideias de patrimônio cultural desenvolvidas no Brasil guardaram grande conexão com a visão europeia, predominante nos séculos XIX e XX, que o encarava como um conjunto de bens corpóreos, autênticos, com caráter monumental ou excepcional.

Com o passar do tempo, evidenciou-se, porém, que essa compreensão, extremamente tacanha, não tinha aptidão para dar conta de toda a variedade e das tensões que sempre marcaram a produção cultural brasileira, construída diuturnamente por diversos segmentos sociais e desenvolvida tanto por escritores, artistas, músicos e sábios quanto por criações anônimas, que simbolizam a "alma popular".

Nesta linha, um grande passo dado pelo texto constitucional de 1988 foi a adoção de uma noção ampla e atual de patrimônio cultural, que, abandonando a visão elitista antes predominante, engloba tanto aspectos materiais quanto imateriais da cultura, tutelando tanto as manifestações eruditas quanto as cotidianas e populares, independentemente do seu excepcional valor universal ou do seu caráter monumental.

Contudo, apesar de a Constituição acolher uma concepção bastante abrangente, pode-se afirmar que não protege a cultura em toda a extensão da sua concepção antropológica, pois só há preservação jurídica dos bens e valores culturais que portem uma referência à identidade, à ação ou à memória dos diferentes grupos formadores da sociedade brasileira. 
Para assegurar os bens que integram o patrimônio cultural brasileiro e regular a sua ampla e livre circulação na sociedade, a Constituição Federal consagra, em seu art. 215, alguns direitos culturais, dispondo que:

Art. 215 - O Estado garantirá a todos o pleno exercício dos direitos culturais e acesso às fontes da cultura nacional, e apoiará e incentivará a valorização e a difusão das manifestações culturais.

$\S 1^{\circ}$ O Estado protegerá as manifestações das culturas populares, indígenas e afro-brasileiras, e das de outros grupos participantes do processo civilizatório nacional.

$\S 2^{\circ}$ A lei disporá sobre a fixação de datas comemorativas de alta significação para os diferentes segmentos étnicos nacionais.

Embora o art. 215 tenha consagrado a existência de direitos culturais, diante da amplitude do conceito de cultura e da sua proximidade desses direitos com outros direitos culturais, como o direito à educação e o direito das minorias (KAUARK, 2014, p. 122), a tarefa de defini-los e de listar todos os direitos à cultura protegidos constitucionalmente não é nada fácil.

Enquanto direitos fundamentais, pode-se dizer que esses direitos apresentam, pelo menos, uma dupla proteção. Na dimensão de liberdade de ação cultural, assumem o caráter de direito de defesa, assegurando determinadas posições subjetivas do indivíduo em face do Estado, que, neste caso, não pode impedir que o indivíduo viva de acordo com os signos e com os valores de sua cultura. Sob este prisma, qualquer pessoa pode expressar qualquer atividade cultural, intelectual, científica, artística ou de comunicação, desde que não esteja vedada em lei. Essa liberdade pode se manifestar tanto com a participação quanto com o acesso e com a colaboração na formação da própria vida cultural da sociedade. As normas constitucionais que estabelecem essa liberdade encontram-se, além do art. 215 , nos art. $5^{\circ}$, IX e $220, \S \S 2^{\circ}$ e $3^{\circ}$ da Constituição Federal de 1988.

Contudo, como a dimensão de liberdade não é suficiente para assegurar o pleno exercício dos direitos culturais, o art. 215 da Constituição exige determinadas prestações positivas do Estado para tornar o acesso à cultura eficaz, impondo, assim, que o Estado "apoiará e incentivará a valorização e a difusão das manifestações culturais” e, de modo particular, que o Estado "protegerá as manifestações das culturas populares, indígenas e afro-brasileiras, e das de outros grupos participantes do processo civilizatório nacional”. Neste último caso, nota-se que o constituinte foi ainda mais cauteloso, não se contentando com o simples apoio ou incentivo, mas exigindo a proteção das manifestações culturais dos grupos que participaram do processo civilizatório nacional. 
Ao utilizar expressões como "segmentos étnicos nacionais" e "culturas populares indígenas, afro-brasileiras e das de outros grupos participantes do processo civilizatório nacional", a Constituição reconhece a existência de diversas etnias e, dentre estas, diversas culturas, que compõem a identidade cultural brasileira. Desta forma, o ordenamento jurídico brasileiro afirma o pluralismo cultural como valor a ser reconhecido e garantido constitucionalmente (SANTOS, 2003).

Entretanto, assegurar o pluralismo cultural não é o mesmo que negar a existência de uma etnia nacional. Como bem ressalta Darcy Ribeiro (1998, p. 19), existe uma etnia brasileira, formada pela confluência de matrizes raciais distintas, tradições culturais diferentes e diversas formações sociais, que, juntas, compõem um povo novo.

No entanto, não se pode, com isso, afirmar que a cultura brasileira é homogênea ou uniforme. Isso teria como consequência a própria negação do pluralismo cultural no Brasil. A heterogeneidade da cultura brasileira é consequência histórica da fusão dos diversos povos que constituíram a etnia brasileira, onde as diversas nações indígenas que viviam originariamente em nosso território mesclaram-se aos portugueses que ocuparam as nossas terras a partir do século XVI e somaram-se, por fim, aos africanos que foram trazidos, como mão-de-obra escrava, de diversas regiões da África. Além disso, a ausência de uniformidade foi assegurada por três forças diversificadoras, destacadas por Ribeiro (1998, p. 21). Seriam elas:

A ecológica, fazendo surgir paisagens humanas distintas onde as condições de meio ambiente obrigaram adaptações regionais. A econômica, criando formas diferenciadas de produção, que conduziram a especializações funcionais e aos seus correspondentes gêneros de vida. $\mathrm{E}$, por último, a imigração, que introduziu, nesse magma, novos contingentes humanos, principalmente europeus, árabes e japoneses (RIBEIRO, 1998, p. 21).

Sob o império destas três forças, foram construídos tipos bem distintos de brasileiros: os sertanejos do nordeste, os caboclos da Amazônia, os caipiras do Sudeste, os gaúchos do Sul, além de outras formações como os nipo-brasileiros e os ítalo-brasileiros (RIBEIRO, 1998, p. 19), que acentuam o caráter antagônico e plural da nossa cultura e enfatizam a importância do reconhecimento do pluralismo cultural como valor.

Nas palavras de José Afonso da Silva (2001, p. 76), “optar por uma sociedade pluralista significa acolher uma sociedade conflitiva, de interesses contraditórios e antinômicos", que se contrapõe à sociedade monista que "mutila e engendra as ortodoxias opressivas". Esta é a importância do pluralismo cultural: garantir a liberdade individual de escolha dos valores 
culturais a serem seguidos e assegurar a permanência da diversidade cultural, que compõe a cultura brasileira e tornam-na tão rica.

Outro valor destacado pelo texto constitucional é o da democracia participativa no contexto cultural. Neste sentido, o $\S 1^{\circ}$ do art. 216 da Constituição ressalta a importância da colaboração da comunidade que, juntamente com o Poder Público, deverá promover e proteger o patrimônio cultural brasileiro. Aqui, mais uma vez a Constituição afasta-se do mito liberal de separação entre Estado e sociedade civil, retirando a comunidade de uma posição exclusivamente passiva e convocando-a para a defesa do patrimônio cultural.

Como decorrência do pluralismo cultural, da liberdade e da democracia, Santos (2003, p. 71) compreende que todas as manifestações populares devem receber do Poder Público igual tratamento, quanto ao incentivo e apoio para a sua valorização e divulgação. Contudo, este apoio deve ocorrer por mecanismos que favoreçam a livre procura das manifestações culturais, que facilitem o acesso do povo à cultura e que tornem a difusão cultural igualitária e nunca por instrumentos que imponham uma cultura determinada. Neste contexto, também é fundamental que o Estado promova, através de ações voltadas para a ampliação dos meios de difusão artística e promoção de lazer, a democratização da cultura, tentando igualizar os socialmente desiguais (SILVA, 2001, p. 49).

\section{SISTEMA NACIONAL E INSTRUMENTOS DE PROTEÇÃO DA CULTURA}

Ao garantir aos cidadãos o acesso aos direitos culturais, o constituinte de 1988 não se olvidou em estabelecer os principais instrumentos voltados a tutela do patrimônio cultural brasileiro, prevendo no $\S 1^{\circ}$ do art. 216 que “o Poder Público, com a colaboração da comunidade, promoverá e protegerá o patrimônio cultural brasileiro, por meio de inventários, registros, vigilância, tombamento e desapropriação, e de outras formas de acautelamento e preservação".

Critica-se o dispositivo por não ter detalhado, de maneira mais minuciosa, as ações, diretrizes e garantias mínimas a serem desenvolvidas pelo Poder Público para concretização desses direitos, deixando essa tarefa para as leis infraconstitucionais e para a jurisprudência (DRUMMOND; NEUMAYR, 2011, p. 37).

Contudo, parte desses problemas foram superados com a inclusão do $\S 3^{\circ}$ no art. 215 da Constituição, por meio da EC 48/2005, que determinou para o legislador o dever fundamental de elaborar o Plano Nacional de Cultura, voltado ao desenvolvimento cultural do País e à 
integração do poder público, estabelecendo como diretrizes: a defesa e valorização do patrimônio cultural brasileiro; a produção, promoção e difusão de bens culturais; a formação de pessoal qualificado para a gestão da cultura em suas múltiplas dimensões; a democratização do acesso aos bens de cultura e a valorização da diversidade étnica e regional.

Este parágrafo, sem dúvidas, é de grande importância e representa um grande avanço na matéria, pois fixa balizas que devem nortear a implantação dos direitos culturais no Brasil. Mais recentemente, a EC 71/2012 instituiu o Sistema Nacional de Cultura - SNC, um conjunto de órgãos e entidades voltados para a criação, coordenação e execução de políticas culturais no país.

Além dos instrumentos mencionados expressamente pelo texto constitucional, vale destacar a importância da tutela penal e da imposição de sanções administrativas, aprofundadas em capítulos específicos desta obra, na proteção do patrimônio cultural. De fato, a Lei $\mathrm{n}^{\circ}$ 9.605/98 (Lei de Crimes Ambientais) inovou ao dedicar uma seção específica para os crimes contra o ordenamento urbano e o patrimônio cultural e ao oferecer um amplo repertório de sanções para as infrações administrativas contra o meio ambiente.

Do mesmo modo, todo comportamento ou atividade que danifique bens que integrem o nosso patrimônio cultural, sujeitarão os infratores, além das sanções administrativas e penais cabíveis, à obrigação de reparar os danos causados de forma objetiva, nos termos do parágrafo único do art. 14 da Lei 6.938/1981.

Neste tópico, serão analisados de maneira sintética, além o sistema nacional de cultura, os três principais mecanismos de tutela à disposição do Poder Público para a proteção e difusão dos bens culturais na sociedade brasileira: os planos de cultura, o tombamento e o registro.

\subsection{Planos de Cultura}

Os planos de cultura "são um conjunto de princípios, objetivos, diretrizes, estratégias e metas que devem orientar o poder público na formulação de políticas culturais e na definição de programas e projetos" (KAUARK, 2014, p. 129). Tratam-se de importantes instrumentos de planejamento das políticas culturais, que se bem implantados, podem representar um avanço considerável para o desenvolvimento da cultura no País.

Após a sua inserção no texto constitucional, o Plano Nacional de Cultura - PNC foi instituído pela Lei $\mathrm{n}^{\circ} 12.343$ de 02 de dezembro de 2012, que pretende assegurar estabilidade 
para uma política pública historicamente marcada por ausências, autoritarismo e instabilidade (RUBIM, 2008).

De fato, com um prazo de duração de dez anos, o PNC trouxe para o País a possibilidade concreta de construção de uma política de Estado no âmbito cultural com princípios, objetivos claros e capaz de ultrapassar a periodicidade dos governos.

Esta Lei acolhe como princípios da Política Nacional de Cultura $\left(\operatorname{art.~} 1^{\circ}\right)$ a liberdade de expressão, criação e fruição; a diversidade cultural; o respeito aos direitos humanos; o direito de todos à arte e à cultura; o direito à informação, à comunicação e à crítica cultural; o direito à memória e às tradições; a responsabilidade socioambiental; a valorização da cultura como vetor de desenvolvimento sustentável; a democratização das instâncias das políticas culturais; a responsabilidade dos agentes públicos pela implementação das políticas culturais; a colaboração dos agentes públicos e privados para o desenvolvimento da economia da cultura e, por fim, a participação e controle social na formulação e acompanhamento das políticas culturais. Ao fazê-lo, o texto legal aproxima-se dos princípios constitucionais norteadores das ações culturais, que preconizam o pluralismo cultural, a liberdade e a democracia no acesso e na construção de políticas públicas relativas a esses bens.

Também apresenta uma lista com doze deveres dirigidos ao poder público para a materialização dos direitos culturais (art. $3^{\circ}$ ), com destaque para a formulação de políticas públicas e programas que conduzam à efetivação dos objetivos, diretrizes e metas do Plano; o fomento à cultura de forma ampla, por meio da difusão e da adoção de incentivos e subsídios econômicos e financeiros para a sua promoção; a garantia da preservação do patrimônio cultural brasileiro e a organização de instâncias consultivas e de participação da sociedade para contribuir na formulação e debater estratégias de execução das políticas públicas de cultura.

Desse modo, observa-se que um mérito do novo marco legal está em tornar mais claros os direitos culturais assegurados pelo nosso ordenamento e precisar as ações que devem ser adotadas pelos entes federados para a sua concretização.

Como recordam Drummond e Neumayr (2011, p. 38-39), embora os comandos ali inseridos voltem-se mais para a atuação dos Poderes Legislativo e Executivo, não se pode esquecer que, enquanto direitos fundamentais, os direitos culturais podem ser aplicados direta e imediatamente pelo Poder Judiciário, como já ocorreu em alguns casos paradigmáticos como o que discutiu a constitucionalidade da farra do boi catarinense, a legalidade dos rodeios paulistas e a infraestrutura dos bailes funks cariocas, onde os tribunais tiveram a oportunidade 
de confrontar o direito à manifestação cultural com outros direitos como o da proteção dos animais contra atos cruéis e da segurança da população.

A partir das balizas trazidas pelo Plano Nacional de Cultura, os Estados, Municípios e Distrito Federal tem discutido e formulado os seus planos estaduais e municipais. Contudo, para que a efetividade dos planos de cultura seja alcançada é indispensável tanto a formulação de metas claras, quanto o aumento dos investimentos voltados para o setor, a ampliação de sua capacidade de gestão e a articulação de competências entre os diversos agentes (KAUARK, 2014, p. 129). Para tanto, a instalação do Sistema Nacional de Cultura, tal como preconizado pelo art.216-A da Constituição, será fundamental.

\subsection{Sistema Nacional de Cultura - SNC}

Uma das grandes dificuldades na gestão dos bens culturais no Brasil decorria da ausência de um Sistema Nacional de Cultura no país, que fixasse os órgãos responsáveis pela criação, coordenação e execução das políticos de cultura, definindo de modo adequado as suas esferas de sua atuação e fixando mecanismos de cooperação entre eles.

Suprindo essa lacuna, a EC 71/2012 entrou em vigor, inserindo o art. 216-A na seção constitucional da cultura, com o claro objetivo de dotar o ordenamento jurídico brasileiro de um arcabouço institucional voltado para a elaboração e implementação de ações na esfera cultural.

De acordo com o citado dispositivo, o SNC é organizado em regime de colaboração, de forma descentralizada e participativa, com a missão instituir um processo de gestão e promoção conjunta de políticas públicas de cultura, democráticas e permanentes, pactuadas entre os entes da Federação e a sociedade e como objetivo primordial promover o desenvolvimento humano, social e econômico com pleno exercício dos direitos culturais.

Segundo o $\$ 2^{\circ}$ do artigo, a estrutura do SNC é formada, nas respectivas esferas da federação, pelos órgãos gestores da cultura, pelos conselhos de política cultural, pelas conferências de cultura, pelas comissões intergestores, pelos planos de cultura, pelos sistemas de financiamento à cultura e de informações e indicadores culturais, pelos programas de formação na área da cultura e pelos sistemas setoriais de cultura, cabendo à Lei federal dispor sobre a sua regulamentação e articulação com os demais sistemas nacionais ou políticas setoriais de governo. 
A instalação do SNC traz o desafio de, juntamente com o Plano Nacional de Cultura, criar a estabilidade necessária para a gestão, desenvolvimento e difusão dos bens culturais no território brasileiro. Contudo, apesar dos avanços que a política cultural alcançou nos últimos anos, ainda são enormes os desafios a serem superados para torná-la efetiva, dentre eles, destacam-se a necessidade de desenvolvimento de um programa contínuo de formação e de qualificação de profissionais para atuar na área (RUBIM, 2008, p. 65) e o fato de que sua concretização demanda quantidade razoável de recursos, assim como a perenidade das respectivas fontes de financiamento.

Nesta linha, três propostas de emenda constitucional (PECs 310/20004, 150/2003 e 324/2001) estão em tramitação no Congresso Nacional com o objetivo de fixar um percentual mínimo do orçamento de cada ente federado para investimentos na área cultural.

\subsection{Tombamento}

O tombamento é um procedimento administrativo, que tem por fim a preservação de bens, móveis ou imóveis, públicos ou privados, de caráter material, tomados individual ou conjuntamente, mas integrantes do patrimônio cultural brasileiro, que culmina com a sua inscrição em um dos Livros de Tombo previstos no DL 25/1937 (Lei do Tombamento).

Ele decorre do poder de polícia da Administração Pública, que, no exercício de seu dever constitucional de tutelar os bens de valor histórico, artístico e cultural, intervém na propriedade privada, submetendo-lhes a um regime jurídico especial de proteção. Pretende-se, com este instrumento, preservar bens culturais materiais, evitando que a ação ou a omissão dos seus proprietários importe na perda ou deterioração dos valores e significados neles incorporados.

Por isso, uma vez efetuado o tombamento, os bens submetidos à sua proteção não poderão ser destruídos, demolidos ou mutilados nem, sem prévia autorização do Instituto do Patrimônio Histórico e Artístico Nacional - IPHAN, ser reparados, pintados ou restaurados (art. 17 do DL 25/37). Também não poderão ser alienados onerosamente sem que se assegure ao poder público o direito de preferência (art. 22).

O proprietário também assume o dever de realizar obras de conservação e reparo que o bem requerer e, em caso de não ter condições financeiras para realizá-las, fica obrigado a levar o fato ao conhecimento do órgão, sob pena de multa (art. 19). As limitações também alcançam a vizinhança da coisa tombada, que não poderá fazer construção que impeça ou reduza a sua visibilidade nem nela colocar anúncios ou cartazes (art. 18). 
Embora o art. $1^{\circ}$ do DL 25/37 mencione a necessidade de vinculação dos bens a serem tombados a "fatos memoráveis da história do Brasil" ou à presença de um "excepcional valor arqueológico ou etnográfico, bibliográfico ou artístico", de acordo com o texto constitucional, para que sejam objeto de tombamento, basta que esses bens sejam portadores de referência à identidade, ação ou memória dos povos que formaram a civilização brasileira.

Além disso, diversamente do que dispõe o parágrafo primeiro do mesmo artigo, o art. 216 da Constituição Federal de 1988 não exige a inscrição em um dos livros de tombo como pré-requisito para que um bem integre o nosso patrimônio cultural. Desse modo, entende-se que o tombamento não é condição para o reconhecimento do valor cultural de um bem, mas apenas um dos instrumentos previstos em nosso ordenamento para preservá-lo.

Como a proteção dos bens de valor histórico, artístico e cultural foi situada no âmbito da competência comum da União, Estados, Municípios e Distrito Federal, é certo que todos os entes federados possuem atribuição para realizar o tombamento, sendo possível, inclusive, que um mesmo bem desperte interesse tríplice.

Sobre o tema, vale destacar a advertência José Eduardo Ramos Rodrigues (2001, p. 178), para quem a proteção do nosso sistema constitucional volta-se ao patrimônio cultural brasileiro, o que impede o argumento da existência de "patrimônio de interesse estadual ou regional" ou de "interesse municipal ou local” para justificar a omissão dos órgãos de proteção mais organizados diante da perda sistemática de bens culturais que vem ocorrendo nos municípios.

Discute-se, em sede doutrinária, se o tombamento apresenta natureza de servidão ou de limitação administrativa ao direito de propriedade. Neste debate, é importante recordar que os bens culturais, na perspectiva de macrobens ambientais, apresentam sempre titularidade difusa ou coletiva, de modo que o tombamento só afeta a propriedade privada na medida em que serve de suporte físico para a esses valores.

Ademais, como bem recorda Ana Maria Marchesan (2007, p. 215), o tombamento não apresenta natureza de ato expropriatório, consistindo, antes numa decorrência da função social internalizada pelo direito de propriedade.

Por isso, a não ser naquelas hipóteses raríssimas em que o instituto possa gerar o esvaziamento econômico do bem, parece incabível a possibilidade de indenização aos proprietários de móveis ou imóveis tombados. Nestes casos, para intentar a ação com o objetivo de requerer a indenização o proprietário deve observar o prazo de 5 anos previsto no DecretoLei n. 3365, de 21 de junho de 1941, que dispõe sobre desapropriações por utilidade pública. 
Segundo Marés (1997), o tombamento ainda se apresenta como um ato de efeitos diferenciados na medida em que é constitutivo dos efeitos determinados na lei, ou seja, homologado o bem, passa este à condição de imune contra atos do proprietários ou de terceiros que o possam mutilar, alterar ou destruir e é declaratório de um valor cultural que o bem já possuía.

O tombamento pode ser classificado quanto à eficácia, aos destinatários e ao procedimento.

Quanto à eficácia, poderá ser provisório, conforme esteja o processo iniciado pela notificação ou definitivo se concluído pela inscrição dos referidos no competente Livro do Tombo, nos termos do artigo 10 do Decreto n. 25/37.

No que se refere aos destinatários, poderá ser geral se o bem atingir um conjunto de bens, um bairro, uma cidade ou individual se atingir um bem particular.

No que se refere ao procedimento, poderá ser: a) de ofício: quando o bem for pertencente à União, aos Estados e aos Municípios e se dará por ordem do diretor do Serviço do Patrimônio Histórico e Artístico Nacional, devendo ser notificado à entidade que pertencer, ou sob guarda estiver a coisa tombada, a fim de produzir os necessários efeitos, nos termos dos artigo $5^{\circ}$ do Decreto n. 25/37; b) voluntário: quando a coisa pertencer a pessoa natural ou jurídica de direito privado. Nesse caso, é necessário que o proprietário solicite o tombamento e a coisa se revista dos requisitos necessários para constituir parte integrantre do patrimônio histórico e artístico nacional, a juízo do Conselho Consultivo do Serviço do Patrimônio Histórico e Artístico Nacional, ou sempre que o mesmo proprietário anuir, por escrito, à notificação, que se lhe fizer, para inscrição da coisa em qualquer dos livros do Tombo; c) compulsório: quando a coisa pertencer a pessoa natural ou jurídica de direito privado e esta se recusar a anuir à inscrição da coisa.

O tombamento pressupõe uma avaliação do valor cultural do bem submetido a esse procedimento administrativo, que, durante muito tempo, foi realizada, politicamente, pelos governantes, a quem cabia a escolha dos bens que deveriam ou não integrar o patrimônio cultural brasileiro (RODRIGUES, 2001, p. 178). Posteriormente, essa tarefa passou a ser realizada por especialistas, portadores de um notório conhecimento sobre a matéria e que eram reunidos em órgãos colegiados integrantes da estrutura organizativa do Estado. Em razão da evidente ausência de neutralidade na escolha realizada, muitos bens que apresentavam uma arquitetura eclética deixaram se ser preservados (RODRIGUES, 2001, p. 178). Por isso, a luz do texto constitucional, que determina a participação popular na proteção do patrimônio cultural 
brasileiro e da necessidade de manutenção do pluralismo cultural, entende-se na linha de José Eduardo Ramos Rodrigues (2001, p. 178), que a melhor saída está na atuação da coletividade que deve, conjuntamente com o poder público, participar da escolha dos bens a serem preservados.

São exemplos de bens tombados pelo IPHAN no Brasil, os centros históricos de Laguna e São Francisco do Sul, assim como a Ilha do Campeche (em razão do seu valor como patrimônio arqueológico e paisagístico) em Santa Catarina; o conjunto arquitetônico, paisagístico e urbanístico do centro histórico de Salvador e a Igreja do Senhor do Bonfim na Bahia; o conjunto arquitetônico e urbanístico da Cidade de Ouro Preto em Minas Gerais; o Cristo Redentor, o Morro do Pão de Açúcar e o Jardim Botânico no Rio de Janeiro e a Estação da Luz em São Paulo.

\subsection{Registro}

Trata-se do mais importante instrumento de preservação do patrimônio cultural imaterial, que tem como finalidade reconhecer e valorizar as mais diversas manifestações culturais que portem referência à ação dos grupos formadores da sociedade brasileira e apresentem natureza intangível, dando-lhes a mais ampla divulgação.

Diferente dos bens culturais materiais, os bens que integram o patrimônio imaterial apresentam caráter processual ou mutável, o que torna o tombamento um instrumento restrito e inadequado para a sua proteção. A sua tutela não demanda a imposição de limitações administrativas ao direito de propriedade ou de imobilismos, mas a realização de documentação e acompanhamento da sua própria dinâmica (MARTINS, 2014, p. 14). Diante da impossibilidade de "congelar" essas manifestações culturais, a partir do registro, o poder público assume o ônus de inventariar essas práticas, de observar a sua continuidade, divulgando e oferecendo-lhes apoio.

Previsto originalmente na Constituição de 1988, o registro foi disciplinado pelo Decreto $\mathrm{n}^{\circ}$ 3.551/2000. Esse Decreto surgiu a partir da articulação de diversas entidades voltadas à proteção do patrimônio cultural que, em 1997, reunidas num congresso comemorativo dos sessenta anos do IPHAN, realizado em Fortaleza - CE, aprovaram recomendação no sentido de que fosse formado, o mais rápido possível, um grupo de trabalho com a finalidade de propor a disciplina legal do registro (COSTA, 2011, p. 115). 
Critica-se a escolha do decreto como instrumento para a sua regulamentação, pois, embora esta via tenha permitido uma maior agilidade para seu ingresso em nosso ordenamento, além de não ter assegurado uma maior legitimidade para o instituto, impossibilitou a imposição, em sua disciplina, de qualquer restrição a direitos (como seria desejável em relação ao direito de propriedade intelectual) ou de deveres aos sujeitos envolvidos com o bem registrado (MARTINS, 2014; COSTA, 2011).

Segundo o art. $1^{\circ}$ do Decreto $\mathrm{n}^{\mathrm{o}} 3551 / 2000$, o registro dos bens culturais de natureza imaterial deve ser feito em um dos quatro livros previstos no dispositivo, que são: o Livro de Registro dos Saberes; o Livro de Registro das Celebrações; o Livro de Registro das Formas de Expressão ou o Livro de Registro dos Lugares.

Foram definidos tanto requisitos materiais como formais para o registro desses bens, exigindo-se, respectivamente, que além de relevância nacional e continuidade histórica $\left(\S 2^{\circ}\right.$ do art. $1^{\circ}$ ), o legitimado para o requerimento de inscrição apresente descrição pormenorizada do bem a ser registrado, acompanhada de documentação correspondente e com menção a todos os elementos que sejam relevantes do ponto de vista cultural $\left(\$ 2^{\circ}\right.$ do art. $\left.3^{\circ}\right)$.

Quanto ao seu procedimento, de acordo com o art. $3^{\circ}$, as propostas de registro, acompanhadas da documentação técnica deverão ser dirigidas ao Presidente do IPHAN, que após a instrução, deverá submetê-las, juntamente com o parecer do órgão acerca do requerimento de inscrição, ao Conselho Consultivo do Patrimônio Cultural para deliberação.

Antes, porém, o parecer deverá ser publicado no Diário Oficial da União para eventuais manifestações sobre o registro sejam feitas. As manifestações devem acompanhar o processo de registro quando o mesmo for submetido à apreciação do conselho (art. $4^{\circ}$ ). Havendo manifestação favorável do órgão consultivo, o bem deverá ser inscrito no livro correspondente, recebendo, nesta oportunidade, o título de Patrimônio Cultural do Brasil (art. $5^{\circ}$ ).

Como ponto de avanço, na linha do $\S 1^{\circ}$ do art. 216 da Constituição Federal, que prevê a importância da participação social na preservação dos bens culturais, o decreto, de forma inovadora, atribuiu legitimidade às sociedades e associações civis, que ao lado do IPHAN, das instituições vinculadas ao Ministério da Cultura e das Secretarias de Estado, de Município e do Distrito Federal, podem apresentar de proposta de registro de bens imateriais.

Desde a entrada em vigor do Decreto $n^{\circ} 3551 / 2000$, diversos bens culturais imateriais já foram objeto de registro, como são o caso da arte Kusiwa dos Índios Wajãpi (Amapá), do ofício das Paneleiras de Goiabeiras, do samba de Roda no Recôncavo Baiano, do Círio de Nossa Senhora de Nazaré e do ofício das Baianas de Acarajé. 
Por fim, vale destacar que, a despeito da importância da regulamentação do registro como instrumento de tutela do patrimônio cultural intangível, a sua aplicação isolada não é capaz de conferir uma proteção ampla para esses bens, sendo necessária a sua articulação com outras medidas, como é o caso da defesa da propriedade intelectual coletiva.

\section{DIREITOS AUTORAIS E PROTEÇÃO DA CULTURA}

Destaca-se no âmbito das discussões sobre a proteção do patrimônio cultural o papel dos direitos autorais como instrumento de proteção aos aspectos imateriais da cultura. $\mathrm{O}$ direito de autor, espécie de direito de propriedade intelectual, é marcado pela atividade intelectual nos campos literário e artístico, e garante ao criador da sua obra o direito de explorá-la de forma exclusiva durante o prazo de proteção. O uso por terceiros de uma obra autoral, assim, depende de autorização prévia e expressa do autor, por quaisquer modalidades.

Os direitos autorais são constituídos pelo direito de autor e os que lhe são conexos, que possuem as mesmas normas legais, a lei $\mathrm{n}^{\circ}$ 9.610, de 19 de fevereiro de 1998, aplicando aos conexos o que lhe for compatível. Os primeiros estão relacionados a atividade intelectual nos campos literário e artístico e os segundos aos artistas intérpretes ou executantes, dos produtores fonográficos e das empresas de radiodifusão.

Esses direitos são constituídos por uma vertente moral e outra patrimonial. Os direitos morais ${ }^{3}$ são relacionados a "emanação da personalidade do autor com a elaboração, a divulgação e a titulação de sua obra" e os direitos patrimoniais dizem respeito a exploração econômica da obra. O registro da obra autoral é de natureza meramente declaratória, isto é, o direito surge com a criação da obra, que de alguma forma tenha sido expressada ou fixada, e o seu registro tem a função meramente de constituir prova. Tal registro pode ser realizado na Biblioteca Nacional, na Escola de Música, na Escola de Belas Artes da Universidade Federal do Rio de Janeiro, no Instituto Nacional do Cinema, ou no Conselho Federal de Engenharia, Arquitetura e Agronomia.

Os direitos autorais são considerados pela legislação nacional como bens móveis, e os negócios a eles relacionados deverão ser interpretados restritivamente. $\mathrm{O}$ artigo $7^{\circ}$ exemplifica

\footnotetext{
${ }^{3}$ Por exemplo, ter o nome, pseudônimo ou sinal convencional indicado ou anunciado, como sendo autor, na utilização de sua obra; ter garantida a integridade da obra. São ainda inalienáveis e irrenunciáveis.
} 
obras que são protegidas pelo direito autoral ${ }^{4}$, e abarcam grande parte de bens culturais. $\mathrm{O}$ prazo de proteção em relação aos direitos patrimoniais do autor é de setenta anos contados de $1^{\circ}$ de janeiro do ano subsequente ao de seu falecimento e nas obras audiovisuais e fotográficas tal prazo será de setenta anos, a contar de $1^{\circ}$ de janeiro do ano subsequente ao de sua divulgação.

O direito autoral apresenta-se como um grande desafio para políticas nacionais de promoção, preservação e acesso à cultura, tendo em vista que se observa um tratamento maximalista para a proteção destes direitos, o que vem causando prejuízos irreparáveis ao interesse coletivo e ao desenvolvimento do pluralismo cultural. A obra intelectual protegida pelo direito autoral envolve múltiplas facetas. Tem-se, de uma lado, o direito do autor, de outro, o direito de acesso, numa interconexão entre direito privado e interesse coletivo. Em consequência disso, o direito autoral, assim como demais direitos de propriedade intelectual, sempre enfrenta o desafio do equilíbrio entre tais interesses.

Assim, comum encontrar nas legislações internacional e nacionais dispositivos legais que visam não apenas garantir direitos aos titulares de direitos de propriedade intelectual, mas também a previsão de direitos à sociedade, que deve suportar o ônus de tornar um bem público em bem privado. É comum denominar tais direitos que tutelam interesses da coletividade nas legislações de "limitações", a exemplo do que ocorre mesmo com a propriedade material.

As limitações reforçam o caráter não absoluto do direito autoral, pois são regras que dizem respeito a não aplicação do direito de exclusivo do autor, são regras negativas ou regras sobre utilizações livres. Mais do que limites ao direito do autor, tem-se previsão do que não é apoderável, por isso, livre. Consagra-se nas limitações o que a sociedade, por via legislativa, considera como legítimo uso pela coletividade, ao mesmo tempo em que se mantém o reconhecimento do direito daquele que produziu determinada obra. Proteção autoral e utilizações livres soam como dois lados da mesma moeda (ASCENSÃO, 2010).

Ainda assim, os limites dispostos na lei de direitos autoral do Brasil (art. 46), não são adequados para congregar a proteção do patrimônio cultural brasileiro. Isso pode ser observado na impossibilidade de cópia privada, permitida apenas de pequenos trechos, ou de cópia de segurança, no caso de bibliotecas, arquivos e museus, ou de cópia para fins educacionais. E, ainda, nada dizem respeito sobre algumas formas de abusos de direitos que podem ser observados na dificuldade encontrada no acesso ou utilização de obras, do quais se destaca a

\footnotetext{
${ }^{4}$ Os direitos autorais protegem as obras literárias, artísticas e científicas, tais como: textos; audiovisuais; fotografias; desenho, pintura, gravura, escultura, litografia e arte cinética; ilustrações; projetos, esboços e obras plásticas concernentes à geografia, engenharia, topografia, arquitetura, paisagismo, cenografia e ciência; adaptações, traduções; programas de computador.
} 
recusa ou criação de obstáculos não razoáveis feita por titulares e herdeiros, como no caso de obras esgotadas.

Existem tais limitações de ordem intrínseca, próprias da legislação de direito de autor, e, outras, de ordem extrínseca, visto que os limites ao direito autoral também devem ser visto dentro do contexto do ordenamento jurídico ao qual se encontra subordinado (ASCENÇÃO, 1997). Por exemplo, aplica-se ao direito autoral o limite encontrado no princípio da função social da propriedade (art. $5^{\circ}$, XXIII, Constituição Federal), no direito de acesso a cultura (art. 215, Constituição Federal), no direito de acesso a informação (art. $5^{\circ}$, XIV, Constituição Federal), no direito de acesso a educação (art. 205, Constituição Federal), no direito de acesso ao conhecimento (art. 218, Constituição Federal).

Outro fator preocupante é a inexistência de uma política pública voltada para a promoção das obras que se encontram em domínio público, fato que ocorre com o fim do prazo de proteção pelo direito autoral e que permite que tais obras sejam utilizadas livremente, desde que com a preservação dos direitos morais do autor. Verifica-se que o aproveitamento deste acervo cultural, que já padece com prazos de proteção excessivamente longos, necessita ao menos ser objeto de uma base de dados sobre as obras em domínio público, com incentivos e promoção ao seu uso.

O desafio é ainda maior tratando-se das transformações desse ambiente pelas novas tecnologias de informação e comunicação, que podem implicar tanto em acesso quanto em restrição a depender das regras, princípios e valores que são atribuídos aos seus desenvolvimentos e usos. Por exemplo, o livro digital em comparação ao livro de papel ou a biblioteca digital em relação à tradicional biblioteca física talvez sejam os exemplos mais emblemáticos dessa observação. Os meios tradicionais nos dois casos permitem que os livros sejam lidos, feitas anotações e emprestados a terceiros quantas vezes o seu usuário ou seu detentor desejar. As novas tecnologias tanto podem facilitar esse processo quanto dificultá-lo, podem ser criadas regras que tragam melhoramentos à distribuição, à cópia e ao acesso, quanto outras que podem inibir totalmente a cópia, o compartilhamento e o número de vezes e locais de acesso. Essa realidade é provocada pelas conhecidas Technological Protection Measures TPM (Medidas de Proteção Tecnológica, em português) e Digital Rights Management - DRM (Gestão Digital de Direitos, em português), mecanismos permitidos por tratados internacionais, que são ferramentas tecnológicas utilizadas para restringir o acesso e uso da informação digital e que em muitas situações ferem o âmbito das utilizações livres. 


\section{CONCLUSÃO}

A cultura deve ser considerada na sua acepção ampla, integrada ao meio ambiente e como elemento indispensável para o desenvolvimento e a manutenção da identidade brasileira. Observa-se diversos desafios na proteção de seus aspectos materiais e imateriais. Para tanto o quadro regulatório brasileiro previu diversos mecanismos que visam a proteção, valorização e divulgação desse patrimônio.

São primordiais, nesse sentido, o Sistema Nacional de Cultura e os três principais mecanismos utilizados para alcançar tal intento os planos de cultura, o tombamento e o registro. Além desses, os direitos autorais ganham proeminência tanto como um mecanismo que pode ser utilizado de forma alinhada aos princípios de proteção ao patrimônio cultural brasileiro como um dificultador desses objetivos.

Os direitos autorais frente a sua função social devem ser considerados nas políticas públicas nacionais que versam sobre direitos culturais como mais um elemento, juntamente com planos de cultura, o tombamento e o registro, para o seu desenvolvimento. Assim, deve-se afastar o ponto de vista estritamente exclusivistas dos direitos de titulares de direitos de propriedade intelectual. É necessário pensar na necessidade que há de difundir o conhecimento, de preservar a cultura e no valor não apenas econômico dos bens culturais. É a socialização do conhecimento e a preservação do patrimônio já existente que fará com que o patrimônio cultural ambiental brasileiro continue a se desenvolver.

\section{REFERÊNCIAS}

ASCENSÃO, José de Oliveira. O direito autoral em perspectiva de reforma. In: WACHOWICZ, Marcos; DOS SANTOS, Manoel J. Pereira. (Org.). Estudos de direito de autor: a revisão da lei de direitos autorais. Florianópolis: Boiteux, 2010.

ASCENSÃO, José de Oliveria. Direito autoral. 2ed. Rio de Janeiro: Renovar, 1997.

COSTA, Rodrigo Vieira. A dimensão constitucional do patrimônio cultural: o tombamento e o registro sob a ótica dos direitos culturais. Rio de Janeiro: Lumen Iuris, 2011. 
DRUMMOND, Alessandra; NEUMAYR, Rafael (coord.). Direito e cultura: aspectos jurídicos da gestão e produção cultural. Belo Horizonte: Artmanagers, 2011.

KAUARK, Giuliana. Os direitos culturais no Plano Nacional de Cultura. Políticas culturais em revista. Salvador, 2014. Disponível em: http://www.portalseer.ufba.br/index.php/pculturais. Acesso em: 18 de agosto de 2014.

MARCHESAN, Ana Maria Moreira. A tutela do patrimônio cultural sob o enfoque do direito ambiental. Porto Alegre: Livraria do Advogado, 2007.

MARTINS, Fábio Camargo Stamato. O registro do patrimônio cultural imaterial no âmbito do município de São Paulo: proposta de alteração e regulamentação da Lei $\mathrm{n}^{\circ}$ 14.406, de 21 de maio de 2007. In: BENJAMIN, Antonio Herman, LEITE, José Rubens Morato (orgs.). Anais do Congresso Brasileiro de Direito Ambiental (19. : 2014 : São Paulo, SP) Saúde ambiental : política nacional de saneamento básico e resíduos sólidos [recurso eletrônico] / 19. Congresso Brasileiro de Direito Ambiental, 9. Congresso de Direito Ambiental das Línguas Portuguesa e Espanhola, 9. Congresso de Estudantes de Direito Ambiental. São Paulo: Instituto O Direito por um Planeta Verde, 2014. 2v

RIBEIRO, Darcy. O povo brasileiro: a formação e o sentido do Brasil. 2 ed. São Paulo: Companhia das Letras, 1998.

ROCHA, Sophia. Interculturalidade e políticas culturais do Brasil. Políticas culturais em revista. Salvador, 2014. Disponível em: http://www.portalseer.ufba.br/index.php/pculturais. Acesso em: 18 de agosto de 2014.

RODRIGUES, José Eduardo Ramos. Patrimônio cultural: análise de alguns aspectos polêmicos. Revista de Direito Ambiental, ano 6, n. 21, janeiro-março de 200.

RUBIM, Antonio Albino Canelas. Plano Nacional de Cultura em debate. Políticas culturais em revista. Salvador, 2008. Disponível em: http://www.portalseer.ufba.br/index.php/pculturais. Acesso em: 18 de agosto de 2014. 
SANTOS, Luzia do Socorro Silva dos. Multiculturalidade ambiental à luz do sistema constitucional brasileiro: implicações na atividade judicial. 2003. Dissertação (Mestrado em Direito das Relações Sociais). Curso de Pós-graduação em Direito. Pontifícia Universidade Católica de São Paulo, São Paulo.

SILVA, José Afonso da. Ordenação constitucional da cultura. São Paulo: Malheiros, 2001.

WOLFF, Ana Carolina. Da materialidade à imaterialidade: transição que desafia a criação de novos paradigmas para a tutela administrativa e jurisdicional do patrimônio cultural. In: Anais do XXIII Encontro Nacional do Conpedi. Florianópolis, 2014. 